\title{
VERTICAL MARGINAL MISFIT OF THREE AND FOUR UNITS MONOLITHIC ZIRCONIA FIXED PARTIAL DENTURES BEFORE AND AFTER CEMENTATION USING TWO DIFFERENT CEMENTS
}

\author{
Doaa Abd ElAziz A. Helal* and Mohamed Fattouh Abdullah**
}

\begin{abstract}
The aim of this study was to measure the vertical marginal misfit of three and four units FPDs manufactured by Cercon machine before and after cementation by zinc phosphate and resin cements. Twenty monolithic zirconia FPDs group B was fabricated using Cercon machine. FPDs were either three or four units. Standardized metallic dies were scanned to produce the samples. Samples were divided into two main groups where group A was three units FPDs and group B was four units FPDs, each group was divided into two subgroups according to the cement used (subgroup $\mathrm{C} 1$ : Zinc phosphate cement, subgroup C2: Resin cement Variolink N). The vertical marginal misfit of All specimens were measured before and after cementation using stereomicroscope. All data were statistically analyzed. Results showed that the vertical marginal misfit values of monolithic three and four units zirconia FPDs constructed by Cercon machine was clinically acceptable. It was found that using either conventional cementation with zinc phosphate or adhesive resin cementation produced acceptable clinical results, too.
\end{abstract}

KEYWORDS: Vertical marginal misfit, all-ceramic FPDs, Cercon, resin cements and zinc phosphate cements.

\section{INTRODUCTION}

Nowadays, different techniques are used to fabricate ceramic fixed partial dentures (FPDs) either machinably or manually to produce esthetic and durable restorations ${ }^{(1)}$. Computer-aided design/ computer-aided manufacturing (CAD/CAM) can be considered the least technique that relays on the laboratory technician skills ${ }^{(2)}$. zirconia -based FPDs can be considered as an alternative to metal ceramic FPDs in the anterior and posterior areas ${ }^{(3)}$. Using monolithic zirconia restorations is a successful treatment option that has many advantages including: accuracy with reduced need to occlusal adjustments, durability as no risk of veneering porcelain fracture and fulfill the patient needs for functional and esthetic restorations ${ }^{(4)}$. Moreover,

\footnotetext{
* Lecturer of Fixed Prosthodontics, Fixed Prosthodontics Department, Faculty of Dentistry, Benisuef University, Benisuef, Egypt.

** Assistant Professor of Fixed Prosthodontics, Department of Fixed Prosthodontics, Faculty of Dentistry, Cairo University, Giza, Egypt.
} 
using monolithic zirconia restorations, which doesn't require a ceramic veneering, produces restorations that have accurate margins. As it was reported that ceramic veneering of zirconia restorations affects the marginal and internal adaptation of four units zirconia restorations ${ }^{(5)}$.

Cercon is CAD/CAM system that fabricates copings, frameworks and full anatomical allceramic restorations made of Y-TZP zirconia (yttria-stabilized tetragonal zirconia polycrystals). The system can provide highly esthetic and durable restorations ${ }^{(6)}$. From clinical point of view, the esthetic parameters, mechanical Properties and marginal fit are very important factors for ensuring longevity of ceramic restorations. Excellent marginal fit of fixed restorations will decrease plaque accumulation and occurrences of periodontal diseases leading to clinical success ${ }^{(7)}$. An acceptable marginal gap for ceramic restorations should be less than $120 \mu \mathrm{m}$, as marginal misfit of more than $120 \mu \mathrm{m}$ will lead to plaque buildup, dissolution of luting cements, caries, pulp inflammation, and periodontal disease $^{(8,9)}$. Nawafleh et $\mathrm{al}^{(10)}$ reported that there is no evidence about an optimum fit of contemporary systems, with a diverse range between 7.5 and $206.3 \mu \mathrm{m}$. Marginal fit of fixed restorations can be affected by various factors such as thickness of the die spacers, type of finish lines, processing techniques and the choice of luting cements. Luting cements occupy the interface between the restoration and the prepared teeth reducing the marginal misfit to a greater extent. The commonly used luting cements for all-ceramic restorations mainly are resin modified glass ionomer and resin cements and zinc phosphate cements ${ }^{(11)}$. Reich et $\mathrm{al}^{(12)}$ measured in vivo-study the marginal and internal fit of Lava 3-units FPDs by replica technique, the mean marginal gap of Lava FPDs was $65 \mu \mathrm{m}$, nearly similar to those of metal-ceramic FPDs also, Beuer et al ${ }^{(13)}$ also reported that the accuracy of the Lava CAD/CAM system has accepted margin clinically. Vigolo and Fonzi ${ }^{(14)}$ microscopically analyzed marginal fit in zirconia 4-unit FPDs at 50X magnification, the mean marginal gap of the Everest system was $65.49 \mu \mathrm{m}$ with acceptable marginal gap compared to the metal-ceramic restorations. However, Kohorst et al ${ }^{(15)}$ found that the mean marginal gap of the Everest system was $112.8 \mu \mathrm{m}$. And Abduo's (16) reported that the average value of the absolute marginal discrepancy for zirconia FPDs made with Everest systems was $148.8 \mu \mathrm{m}$. To the present authors' knowledge, no studies have been published that evaluated marginal misfit of three and four units Cercon FPDs, The purpose of this in vitro study was to measure and compare the marginal misfit of CAD/CAM Cercon three and four units FPDs before and after cementation using zinc phosphate or resin cement.

\section{MATERIALS AND METHODS}

A total of 20 monolithic zirconia fixed partial dentures (FPDs) were fabricated using CERCON machine. FPDs were either 3 units (replacing missing upper second premolar), named group A or 4 units FPDs( replacing missing upper second premolar and first upper molar), named group B. Each group consisted of 10 FPDs that were randomly divided into 2 sub-groups $(\mathrm{C} 1, \mathrm{C} 2)$ according to the used type of luting cement. Each subgroup contains 5 FPDs, where $\mathrm{C} 1$ is subgroups where FPDs were cemented by Zinc phosphate cement (Adhesor fine, Spofa dental, Czech Republic), while for C2 subgroup FPDs were cemented by resin cement, (variolink N, Ivoclar -Vivadent Co., Lichtenstein) (Table 1).

TABLE (1) Showing experimental samples distribution.

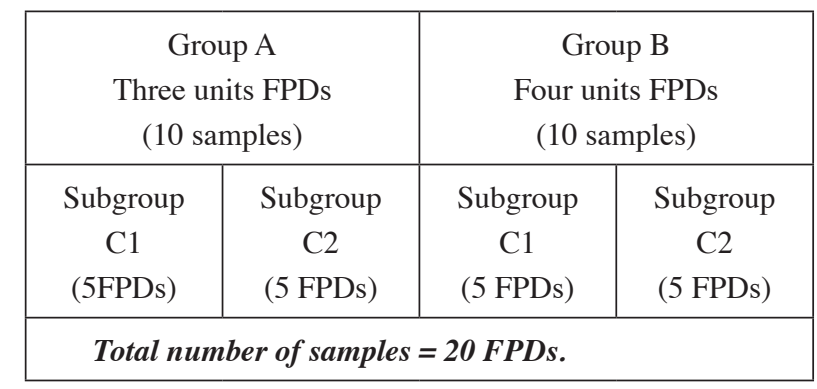


Two stainless steel models (one for each group) representing prepared abutments were prepared using engineering lathe (Automatic feedback lathe- BV20B-L Bengu Dome Siticmaxhime tool, China). Abutments were prepared to be $5 \mathrm{~mm}$ in height and have $1 \mathrm{~mm}$ shoulder finish lines and was prepared with 12 degrees convergence angles. Prepared abutments were screwed to a stainless steel base while being spaced with a suitable pontic distance to represent a case of missing second premolar (group A) and another case of missing second premolar and first molar (group B). For each model 10 impressions were made using polyether impression material (Impergum Penta,3M ESPE, USA). Impressions were poured using epoxy resin material (Table Top Epoxy Resin, clear crystal, USA). Each model was duplicated to a stone model which was scanned using Cercon Eye, then FPDs designing was done using Cercon Art. FPDs were constructed using CERCON machine then placed on their epoxy resin models (Fig. 1).

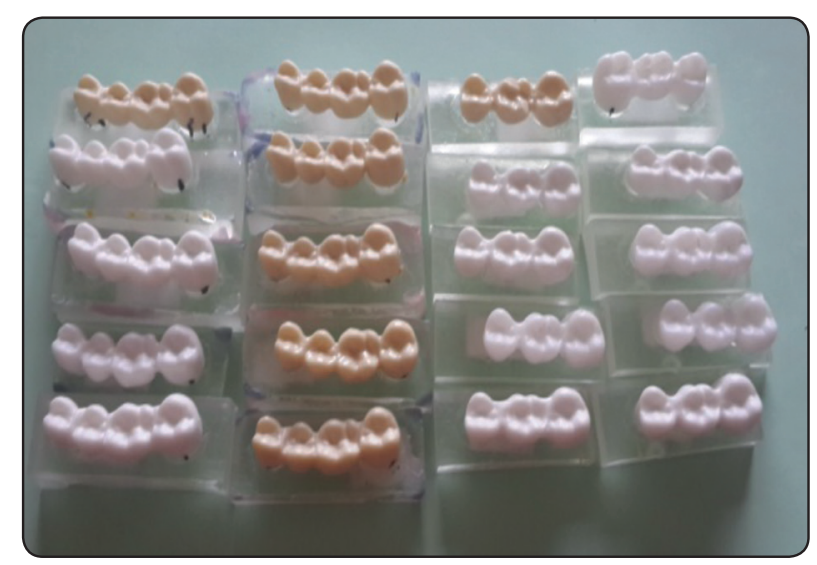

Fig. (1) Twenty monolithic FPD samples that were used in the study

After placing the FPD samples on the epoxy resin models, all the retainers margins were scanned using a stereomicroscope (MA 100, Nikon CO., Japan) to measure the vertical marginal misfit (discrepancy). Scanning was done at 6 positions (at the 4line angles, mid facial , mid lingual). Readings of the marginal discrepancy were done using image analysis software (Omnimet, Buehler, USA) using magnification of $50 \times$.All readings were recorded and an average value was measured for each bridge, by measuring the mean marginal discrepancy values of both retainers. The obtained values were recorded to represent the mean vertical marginal misfit of each FPD sample precementation. The measuring locations were marked previously with an indelible marking pen to assure measuring the marginal discrepancy at the same location pre and post cementation.

Cementation of FPD samples was done following manufacturer's recommendations. FPDs were placed under a static load of $3 \mathrm{Kg}$ during setting of the cements to assure complete seating of the bridge on the dies (Fig. 2). Measuring the vertical marginal misfit for both retainers of each bridge was repeated again after cementation. The vertical marginal misfit values were measured at the previously marked six locations for each retainer and an average value, for each FPD, was recorded to represent the mean vertical marginal misfit of each FPD sample post cementation. (Fig. 3)

All FPDs were stored in deionized water in an incubator (QWJ500, Queue SystemsInc. USA) so that samples were maintained at oral temperature at $37^{\circ} \mathrm{C}$. Samples were removed 24 hours before measurements were taken.

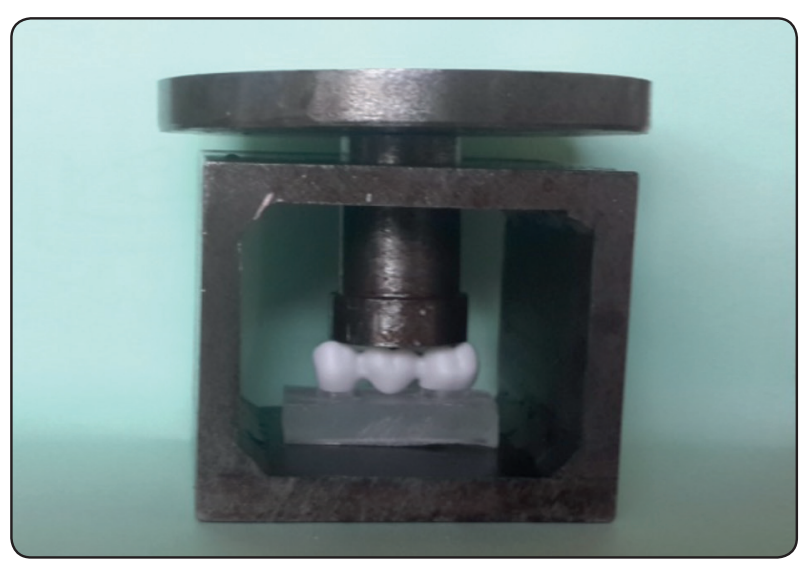

Fig. (2) Cementation of bridge under 3kgm Load. 


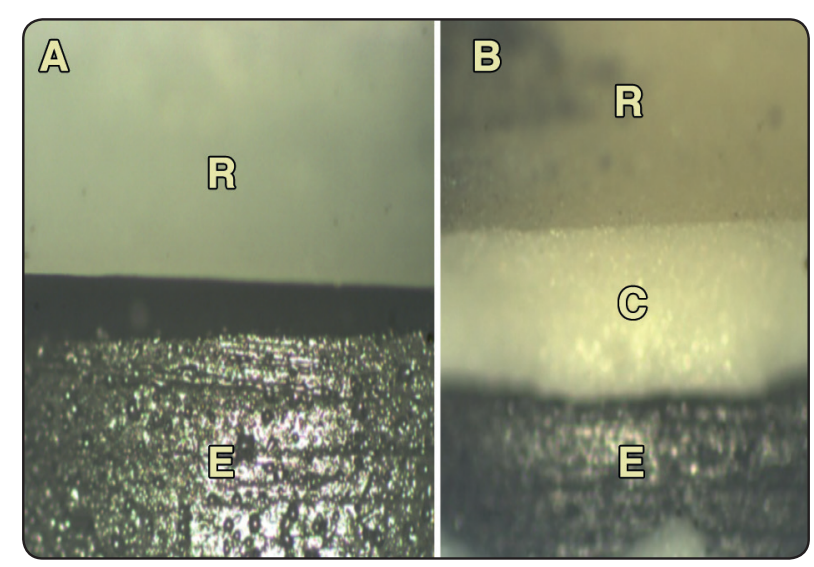

Fig. (3) Measurment of marginal misfit using stereomicroscope. A before cementation, $\mathrm{B}$ after cementation. Where $\mathrm{R}$ is the retainer, $\mathrm{C}$ is the cement, and $\mathrm{E}$ is the epoxy resin abutment margin.

The average values of the vertical marginal misfit for all FPD samples, pre and post cementation, were tabulated and statistically analyzed.

\section{RESULTS}

Collected data were tabulated and statistically analyzed using Wilcoxon rank sum test to study the effect of the individual factors and the interaction between different factors.
Using zinc phosphate cementation, subgroup $\mathrm{C} 1$, did not has any statistical significant effect on increasing the vertical marginal gap values for both groups A and B, as shown in Table 2 .

Also, there was no statistical significant difference in the vertical marginal misfit between group $\mathrm{A}$ and $\mathrm{B}$ whether pre or post cementation using zinc phosphate cement.

Using variolink resin cement, subgroup C2, did not has any statistical significant effect on increasing the vertical marginal misfit values for both groups A. However there was a statistically significant increase in the vertical marginal misfit for group B after cementation, as shown in table 3.

Also, there was no statistical significant difference in the vertical marginal misfit between group A and $\mathrm{B}$ whether pre or post cementation using Variolink resin cement.

For 3 units bridges (group A) using either zinc phosphate cement ( subgroup C1) or variolink resin cement (subgroup $\mathrm{C} 2$ ) for cementation did not has any statistical significant effect on increasing the vertical marginal misfit values. As shown in table 4.

TABLE (2) Vertical marginal misfit measurement for 3 and 4 units zirconia bridge before and after cementation using zinc phosphate cement subgroup $\mathrm{C}$ 1:

\begin{tabular}{|c|c|c|c|c|}
\hline \multicolumn{2}{|c|}{ Units } & Before & After & p-value \\
\hline Group A (3 units) & Mean \pm SD & $37.3 \pm 18.25$ & $60.4 \pm 30.4$ & $0.2(\mathrm{NS}) \#$ \\
\hline Group B (4 units) & Mean \pm SD & $49.6 \pm 24.8$ & $83.3 \pm 30.9$ & $0.1(\mathrm{NS}) \#$ \\
\hline \multicolumn{2}{|c|}{ p-value } & $0.4(\mathrm{NS}) \# \#$ & $0.3(\mathrm{NS}) \# \#$ & \\
\hline
\end{tabular}

\#wilcoxon matched pairs signed rank test

\#\#wilcoxon rank sum test

TABLE (3) Vertical marginal misfit measurement for 3 and 4 units zirconia bridge before and after cementation using resin cement subgroup $\mathrm{C} 2$ :

\begin{tabular}{|l|l|l|l|l|}
\hline \multicolumn{2}{|l|}{ Units } & Before & After & p-value \\
\hline Group A(3 units) & Mean \pm SD & $63.8 \pm 20.9$ & $81.4 \pm 25.01$ & 0.3 (NS)\# \\
\hline Group B (4 units) & Mean \pm SD & $42.9 \pm 6.29$ & $59.5 \pm 8.34$ & $0.02 * \#$ \\
\hline p-value & $0.06(\mathrm{NS}) \# \#$ & $0.1(\mathrm{NS}) \# \#$ & \\
\hline
\end{tabular}


TABLE (4) Vertical marginal misfit measurement for 3 units zirconia bridge before and after cementation using zinc phosphate and resin cement:

\begin{tabular}{|c|c|c|c|}
\hline \multicolumn{2}{|c|}{ Cement } & Before & After \\
\hline Zinc phosphate & Mean \pm SD & $37.3 \pm 18.25$ & $60.4 \pm 30.4$ \\
\hline Resin & Mean \pm SD & $63.8 \pm 20.9$ & $81.4 \pm 25.01$ \\
\hline \multicolumn{2}{|c|}{ p-value } & $0.06(\mathrm{NS}) \# \#$ & $0.3(\mathrm{NS}) \# \#$ \\
\hline
\end{tabular}

\#\#wilcoxon rank sum test

For 4 units bridges (group B) using either zinc phosphate cement (subgroup C1) or Variolink resin cement (subgroup C2) did not has any statistical significant effect on increasing the vertical marginal misfit values. As shown in table 5 .

TABLE (5) Vertical marginal misfit measurement for 4 units zirconia bridge before and after cementation using zinc phosphate and resin cement:

\begin{tabular}{|c|c|c|c|}
\hline \multicolumn{2}{|c|}{ Cement } & Before & After \\
\hline Zinc phosphate & Mean \pm SD & $49.6 \pm 24.8$ & $83.3 \pm 30.9$ \\
\hline Resin & Mean \pm SD & $42.9 \pm 6.29$ & $59.5 \pm 8.34$ \\
\hline \multicolumn{2}{|c|}{ p-value } & $0.6(\mathrm{NS}) \# \#$ & $0.1(\mathrm{NS}) \# \#$ \\
\hline
\end{tabular}

\#\#wilcoxon rank sum test

Results of all subgroups are shown in the following figure (Fig. 4).

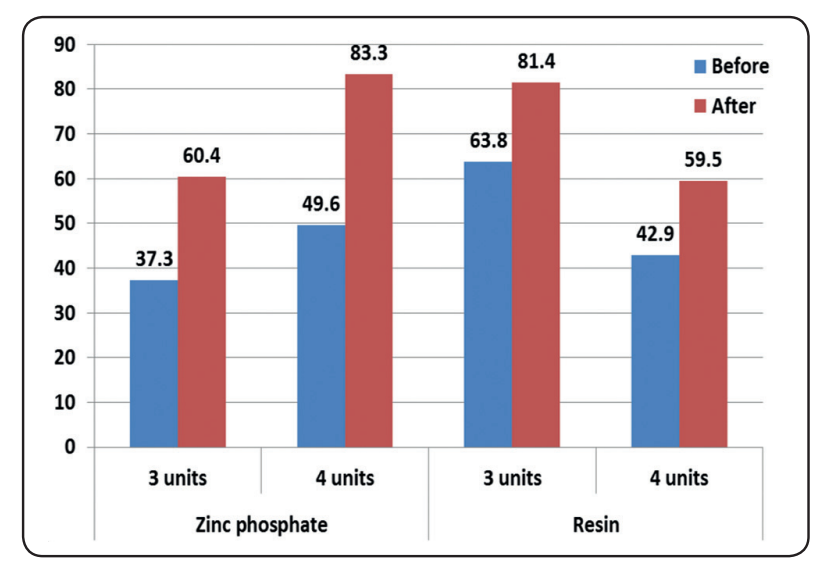

Fig. (4) Vertical marginal misfit measurement for 3 and 4 units zirconia bridge before and after cementation using zinc phosphate and resin cements:

\section{DISCUSSION}

This in-vitro study evaluated the vertical marginal misfit (discrepancy) of three and four units' zirconia FPDs pre and post cementation using two different cements. Obtained data supports acceptance of the null hypothesis that no differences would be found, regarding the vertical marginal misfit, between three and four units zirconia FPDs pre and post cementation with the used two different cements.

in-vitro study helped to standardize the preparation design, the manufacturing technique, ease of marginal evaluation and the restorations performance resulting in a reliable assessment of the margins. However, the in vitro study cannot simulate the clinical conditions that surely affect the restorations and the luting cement bonding (17).

Either chamfer or shoulder finish lines marginal configuration has no significant difference on marginal misfit of zirconia restorations made using Cercon machine ${ }^{(18)}$. In this study, dies were prepared to have a $1 \mathrm{~mm}$ shoulder finish line and an average convergence angle of twelve degrees. Stainless steel dies were used to ensure standardization of specimens shape and dimensions.

Grenade et al in 2011(19) concluded that manufacturing processes of single tooth zirconia copings had affected both the internal and marginal fit. So that, all the FPDs were manufactured using the same technique using Cercon machine.

Measurements of the marginal misfit were done while the FPDs were placed on the epoxy resin dies because measurements were taken before and after cementation on the dies. Also, performing measurements on epoxy models allowed measuring the marginal misfit from both buccal and lingual sides with accuracy. Marginal adaptation was evaluated by external measurements taken by direct viewing which is a non -invasive technique that allowed taking measurements pre and post cementation at the exact same locations. Measuring 
the marginal misfit post cementation was done to study the effect of different cements on increasing the marginal discrepancy. The vertical marginal gap measurements can be used to quantify the accuracy of restorations fit ${ }^{(20)}$. Also, the vertical marginal misfit can affects the cement exposure thus, it is more clinically significant than the horizontal misfit (21). Microscopic measurements used in this research allowed measuring of the marginal misfit in the vertical dimension only. As the marginal misfit can vary at different locations ${ }^{(22)}$ thus, a mean value of 6 measurements for each retainer was recorded before and after cementation. Then, for each FPD, a mean value of the marginal misfit was calculated and recorded.

In this study the vertical marginal misfit did not exceed $83.3 \mu \mathrm{m}$ for all tested groups. The obtained mean marginal gap measurements for all subgroups were within the clinically accepted threshold of ceramic restorations marginal gaps as reported by maclean and Fraunhofer ${ }^{(23)}$.

The use of conventional cementation using glass ionomer or adhesive resin cementation was found to have no relevant clinical difference on survival rate of lithium disilicate crowns ${ }^{\text {(24) }}$.In this study the used cements were zinc phosphate as a conventional cement and Variolink as an adhesive resin cement to test their effect on the vertical marginal misfit. Due to the high flexural strength of zirconia restorations they can be conventionally cemented using either zinc phosphate, glass ionomer or resin modified glass ionomer or resin cemented. As zirconia is not etchable, so bonding requires a pretreatment for the restorations ${ }^{(25)}$.

In this study, all FPDs were manufactured using Cercon machine. It is reported that digital method of manufacturing ceramic restorations can exceeds the clinical acceptance values of vertical marginal fit that surpasses the vertical marginal fit of conventionally fabricated ceramic crowns $(26,27)$ .All FPDs were made from zirconia. It was reported that the marginal and internal fit of copings made by zirconia, Lithium disilicate IPS e.max press and nickel chromium alloy were within the clinically acceptable range ${ }^{(28)}$. Zirconia was reported to be suitable for fabrication of posterior crowns, longspan FPDs and implant abutments ${ }^{(25)}$.

As chipping of veneering porcelain is an ongoing problem with zirconia based all ceramic restorations thus the use of monolithic zirconia restorations (no veneering porcelain) at non esthetic areas is a solution to overcome this common problem ${ }^{(25)}$. Moreover, zirconia ceramic-based anatomic contour (monolithic) restorations was found to show greater passivity of fit compared to ceramic veneered $\mathrm{CAD} /$ CAM fabricated zirconia ceramic frameworks ${ }^{(29)}$. Therefore monolithic restorations were used in this study. In this research the mean vertical marginal misfit, for all test samples, was found to be $54.8 \mu \mathrm{m}$, however the mean vertical marginal misfit for four units FPDs only was $58.8 \mu \mathrm{m}$ was in accordance to the values obtained by Reich et al in 2008 where he found a marginal misfit of $77 \mu \mathrm{m}$ of zirconia four units posterior FPDs ${ }^{(30)}$. Martinez-Rus F. et al in $2011^{(31)}$ reported that the mean marginal misfit for copings made by Cercon was $13.15 \pm 3.01 \mu \mathrm{m}$ which was found to be within the range of clinical acceptance $(120 \mu \mathrm{m})$. However, in other studies the marginal discrepancy of fixed restorations made by Cercon was $80-189 \mu m^{(32,33)}$.The variation in the results between the studies could be referred to variation of the methods used to assess the marginal discrepancy. It was reported that a marginal misfit in the range of $100 \mu \mathrm{m}$ can be considered clinically acceptable with regard to the expected restorations longevity ${ }^{(34,35)}$.The results obtained in this study showed that the vertical marginal misfit values for both 3 units and 4 units FPDs were within the clinically acceptable range, and there was no statistically significant difference between them pre and post cementation. 


\section{CONCLUSIONS}

Within the limitations of this study the following could be concluded.

1- The vertical marginal misfit values of monolithic three or four units zirconia FPDs constructed by Cercon machine was clinically acceptable.

2- Using either conventional cementation with zinc phosphate or adhesive cementation with Variolink $\mathrm{N}$, produced acceptable clinical results.

3- There was no statistical significant difference in the vertical marginal misfit of both three and four units FPDs pre and post cementation.

\section{REFERENCES}

1- Conrad HJ, Seong WJ, Pesun IJ. Current ceramic materials and systems with clinical recommendations: a systematic review. J. Prosthet. Dent. 2007;98: 389-404.

2- Strub JR, Rekow ED, Witkowski S. Computer-aided design and fabrication of dental restorations: current systems and future possibilities. J Am. Dent. Assoc. 2006;137:1289-96.

3- Raigrodski A.,Hillstead M.,Meng G.,Chung K. Survival and complications of zirconia-based fixed dental prostheses: A systematic review.J.of Prosthet. Dent.2012;107:170177 .

4- Carames J.,Suinaga L.,Paul Y.,Perez A, Kang M. Clinical advantages and limitations of monolithic zirconia restorations full arch implant supported reconstruction: case series. int.J.of Dent.2015, article ID 392496.

5- Kohorst P., Brinkmann H.,Dittmer M.,Borchers L.,Stiesch M., Influence of the veneering process on the marginal fit of zirconia fixed dental prostheses. J. Oral Rebhabil. 2010;37:283-291.

6- Denry I, Kelly JR. State of the art of zirconia for dental applications.J. Dent. Mater. 2008;24(3):299-307.

7- White SN, Sorensen JA, Kang SK, Caputo AA. Microleakage of a new crown and fixed partial denture luting agent J. Prosthet. Dent. 1992;67:156-161.

8- Beschnidt SM, Strub JR. Evaluation of the marginal accuracy of different all-ceramic crown systems after simulation in the artificial mouth. J. Oral Rehabil. 1999;26:582-93.
9- Contrepois M, Soenen A, Bartala M, Laviole O. Marginal adaptation of ceramic crowns: a systematic review. J Prosthet Dent 2013;110:447-54-10.

10- Nawafleh N.A., Mack F., Evans J., Mackay J., and Hatamleh M. M. "Accuracy and reliability of methods to measure marginal adaptation of crowns and FDPs: a literature review," Journal of Prosthodontics, vol. 22, no. 5, pp. 419-428, 2013.

11- Kim MJ, Kim KH, Kim YK, Kwon TY. Degree of conversion of two dual-cured resin cements light-Irradiated through zirconia ceramic disks. J Adv Prosthodont. 2013;5(4):464-70.

12- Reich S, Wichmann M, Nkenke E, Proeschel P. Clinical fit of all-ceramic three-unit fixed partial dentures, generated with three different CAD/CAM systems. Eur J Oral Sci 2005;113: 174-9.

13- Beuer F, Naumann M, Gernet W, Sorensen JA. Precision of fit: zirconia three-unit fixed dental prostheses. Clin Oral Investig 2009;13:343-9.

14- Vigolo P, Fonzi F. An in vitro evaluation of fit of zirconiumoxide-based ceramic fout -unit fixed partial dentures, generated with three different CAD/CAM systems, before and after porcelain firing cycles and after glaze cycles. J Prosthodont 2008;17:621-6.

15- Kohorst P, Brinkmann H, Li J, Borchers L, Stiesch M. Marginal accuracy of four-unit zirconia fixed dental prostheses fabricated using different computer-aided design/ computer-aided manufacturing systems. EurJ Oral Sci 2009;117: 319-25.

16- Abduo J, Lyons K, Swain M. Fit of zirconia fixed partial denture: a systematic review. J Oral Rehabil 2010;37:866-76.

17- Ishii R.,Tsujimoto A.,Takamizawa T.,Tsubota K.,Suzuki T., Shimamura Y. Influence of surface treatment of contaminated zirconia on the surface free energy and resin cement bonding. Dent. Mater. J. 2015;34:91-97.

18- Baig M, Tan K, Nicholls J. Evaluation of the marginal fit of a zirconia ceramic computer-aided machined (CAM) crown system. J Prosthet Dent 2010;104:216-227.

19- Grenade C, Mainjot A, Vanheusden A. Fit of single tooth zirconia copings:comparison between various manufacturing processes. J Prosthet Dent 2011;105:249-255.

20- Wolfart S, Wegner S, Al-Halabi A, Kern M, Clinical evaluation of the marginal fit of a new expirmental all-ceramic system before and after cementation. Int. J. Prosthodont 2003;16:587-592. 
21- Sorensen J. A standardizes method for determination of crown margin fiedelity. J.prosthet.Dent.1990;64:18-24.

22- chan C, Harszthy G, Geis-Gerstorfer J, Weber h, Huettermann h. Scanning electron microscopic studies of the marginal fit of three esthetic crowns. Quintessence Int 1989;20:189-193.

23- McLean J, von Fraunhofer J. The estimation of cement film thickness by an in vivo technique. Br Dent J 1971;131: 107-111.

24- Schmitz J, Beani M, effect of different cement types on monolithic lithium disilicate complete crowns with feather-edge preparation design in the posterior region. J Prosthet Dent2015.

25- Al-Amleh B, Lyons K, Swain M. clinical trials in zirconia: a systematic review J Oral Rehab 2010.

26- Jonathan N, Ruse D, Wyatt C. A comparison of the marginal fit of crowns fabricated with digital and conventional methods. . J Prosthet Dent 2014:112:555-560.

27- De Franca D, Morais M, Das Neves F, Barbosa G. influence of CAD/CAM on the fit of implant-supported zirconia and cobalt-chromium fixed dental prosthesis. J prosthet Dent 2015;113:22-28.

28- Pimenta M, Frasca L, Lopez R, Rivaldo E . Evaluation of marginal and internal fit of ceramic and metallic crown copings using $\mathrm{x}$-ray microtomography (micro-CT) technology.J Prosthet Dent 2015;114:223-228.
29- Karl M, Graef F, Wichmann M, Krafft T. Passivity of fit of $\mathrm{CAD} / \mathrm{CAM}$ and copy-milled frameworks, veneered frameworks, and anatomically contoured, zirconia ceramic, implant-supported fixed prostheses. J. Prosthet Dent. 2012;107:232-238.

30- Reich S, Kappe K, Teschner H, Schmitt J. clinical fit of four-unit zirconia Posterior fixed dental prostheses. Eur.J. Oral Sci. 2008;116:579-584.

31- Martinez-Rus F, Suarez M, Rivera B, Pradies G. Evaluation of the absolute marginal discrepancy of zirconia-based ceramic copings. J Prosthet Dent.2011;105:108-114.

32- Beuer F, Aggstaller H, Edelhoff D, Gernet W, Sorensen J. Marginal and internal fits of fixed dental prostheses zirconia retainers. Dent. Mater 2009;25:94-102.

33- Kohorst P, Brinkmann H, Borchers L, Stiesch M. Marginal accuracy of four-unit zirconia fixed dental prosthesesfabricated using differentcomputer-aided design/computer-aided manufacturing systems. Eur J Oral Sci 2009;117:319-325.

34- Groten M, Girthofer S, Probester L. Marginal fit consistency of copy- milled all-ceramic crowns during fabrication by light and scanning electron microscopic analysis. J. Oral Rehail. 1997 ;24:871-881.

35- Gassino G, Barone Monfrin S, Scanu M.,Spina G,Preti G. Marginal adaptation of fixed prosthodontics: A new invitro 360-degree external examination procedure. Int. J. prosthodont.2004;17:218-223. 